\title{
EFEKTIVITAS MASSAGE LUMBAL DAN BREAST MASSAGE TERHADAP KONTRAKSI UTERUS PADA IBU BERSALIN KALA I
}

\author{
THE EFFECTIVENESS OF LUMBAL MASSAGE AND BREAST MASSAGE TO \\ UTERINE CONTRACTION ON FIRST LABOR
}

\author{
Ipang Suparti') , Ullys Indraria Prihadi'2) \\ ${ }^{1) 2)}$ Program Studi Diploma III Kebidanan \\ Akademi Kebidanan Graha Mandiri Cilacap \\ Email : Ipangsuparti@gmail.com
}

\begin{abstract}
ABSTRAK
Penyulit dalam persalinan antara lain adanya kelainan presentasi dan posisi, distosia karena kelainan alat kandungan, distosia karena kelainan janin, dan distosia karena kelainan his. Kelainan his juga dapat terjadi karena his yang tidak adekuat untuk melakukan pembukaan serviks atau mendorong anak keluar. Pijatan pada bagian tubuh agar merangsang pengeluaran oksitosin secara lebih alami dan aktif sehingga diharapkan tidak menimbulkan efek yang berbahaya bagi ibu maupun janin. Jenis penelitian ini menggunakan metode penelitian kuantitatif dengan desain penelitian quasi experimental. Teknik pengambilan sampel pada penelitian ini menggunakan purposive sampling. Sampel pada penelitian ini yaitu ibu bersalin kala I di BPM Siti Sugiharti pada periode Maret-April 2016. Hasil penelitian menunjukkan tindakan massage lumbal yang dilakukan pada ibu bersalin kala I terjadi peningkatan kontraksi uterus sebanyak 20 (95,24\%) responden. Sedangkan pada tindakan breast massage terjadi peningkatan kontraksi uterus sebanyak 19 (90,48\%) responden. Penelitian ini dapat disimpulkan bahwa tindakan massage lumbal yang dilakukan pada ibu bersalin kala I lebih berhasil dibandingkan dengan breast massage. Terdapat perbedaan kontraksi uterus sebelum dan setelah dilakukan Breast Massage terhadap peningkatan kontraksi uterus pada ibu bersalin kala I lama $(t=8,862$, $p$ value $=$ 0,000).
\end{abstract}

Kata Kunci : Breast Massage, Kontraksi Uterus

\section{ABSTRACT}

Difficulties in labor include the presence and presentation abnormalities, dystocia due to abnormalities of the uterus, dystocia due to fetal abnormalities, and dystocia due to his abnormalities. Her abnormalities can also occur due to his inadequate to perform cervical dilatation or to push the child out. Massage on the part of the body to stimulate the oxytocin in a more natural and active so it is expected not to cause harmful effects for mother and fetus. This type of research uses quantitative research method with quasi experimental research design. Sampling technique in this research use purposive sampling. The sample in this research is the first stage maternal mother in BPM Siti Sugiharti from March to April 2016. The results showed that lumbal massage action performed on first labor increased uterine contractions by 20 (95.24\%) of respondents. While on breast massage action increased uterine contractions as much as 19 (90.48\%) of respondents. This study can be concluded that the action of lumbar massage performed on the first labor is more successful than breast massage. There is a difference in uterine contractions before and after Breast Massage is performed on an increase in uterine contractions in the first maternal womb $(t=$ 8.862, $p$ value $=0,000$ ).

Keywords : Breast Massage, Uterine Contractions

Copyright (C) 2017, JK, p-ISSN: 2301-8372, e-ISSN: 2549-7081 


\section{PENDAHULUAN}

Persalinan merupakan suatu hal yang fisiologis pada ibu dimana terjadi serangkaian proses yang berkhir dengan pengeluaran hasil konsepsi. Proses persalinan dipengaruhi oleh lima faktor yaitu kekuatan (power), jalan lahir (pasageway), janin (passenger), psikologis, dan posisi. Proses alamiah tersebut juga memberikan penalaman yang menyenanagkan dan kadang kala tidak menyenangkan. Karena tidak selalunya berjalan normal, dapat terjadi komplikasi persalinan ataupun penyulit dalam persalinan. Upaya non farmakologis merupakan upaya untuk membantu timbulnya kontraksi tanpa bantuan obat atau bahan sintetik lainnya. Dimana upaya tersebut dengan melakukan pijatan pada bagian tubuh agar merangsang pengeluaran oksitosin secara lebih alami dan aktif sehingga diharapkan tidak menimbukan efek yang berbahaya bagi ibu maupun janin. Selain itu terapi non farmatologis dapat digunakan sebagai pelengkap untuk mendapatkan efek pengobatan farmakologis yang lebih baik.

\section{METODE PENELITIAN}

Populasi pada penelitian ini adalah populasi terjangkau, dimana keseluruhan ibu bersalin kala I di BPM Siti Sugharti periode MaretApril 2016. Sampel pada penelitian iniyaitu ibu bersalin kala I di BPM Siti Sugiharti pada periode MaretApril 2016. Teknik sampel pada penelitian ini menggunakn purposive sampling yaitu teknik penentuan sampel dengan pertimbangan tertentu. Teknik analisis statistik dengan teknik pengujian hipotesis menggunakan rumus wilcoxon matched pairs, dimanan untuk menguji hipotesis konparatif dua sampel berpasangan, apabila datanya berbentuk ordinal. Analisis dilakukan denangan membandingkan perbedaan kontraksi yang terjadi sebelum dan sesudah dilakukan massage lumbal dan breast massage. Teknik analisis statistik dengan teknik pengujian hipotesis menggunakan analisa univariat dan bivariat. Penelitian analisia univariat merupakan analisa yang dilaksanakan untuk menganalisis tiap variabel dari hasil penelitian sehingga kumpulan data tersebut dapat menjadi informasi yang berguna berupa ukuran statistik, tabel, dan grafik. Sedangkan analisia bivariat dilakukan untuk menganalisis lebih dari dua variabel dengan membandingkan keberhasilan peningkatan kontraksi yang terjadi dilakukan tindakan massage lumbal dan breast massage (Notoadmodjo, 2005).

Analisa univariat merupakan analisa data untuk mengetahui karateristik masing-masing variabel dengan menggunakan distribusi frekuensi. Analisa data sederhana yang dilakukan antara lain: ukuran nilai tengah (tendensi sentral) dan dispersi (penyimpangan). Ukuran nilai tengah merupakan nilai yang mewakili sekelompok nilai hasil pengamatan.

\section{HASIL DAN PEMBAHASAN}

Hal ini sesuai dengan pendapat Saifuddin (2011) bahwa Hypotonic uterine contraction merupakan kelainan his dengan kekuatan yang lemah / tidak adekuat untuk melakukan pembukaan serviks atau mendorong anak keluar. Diagnosis 
inersia uteri paling sulit ditegakkan pada masa laten.

Kontraksi uterus yang disertai rasa nyeri tidak cukup untuk menjadi dasar utama diagnosis bahwa persalinan sudah dimulai. Incoordinate uterine actionya itu tidak adanya koordinasi antara kontraksi bagian atas, tengah dan bawah menyebabkan His tidak efisien dalam mengadakan pembukaan. Penderita biasanya primigravida, kala I menjadi lama dan dapat diraba jelas pinggir serviks yang kaku. His yang tidak normal dalam kekuatan atau sifatnya menyebabkan rintangan pada jalan lahir yang lazim terdapat pada setiap persalinan, tidak dapat diatasi sehingga persalinan mengalami hambatan atau kemacetan.

Selain itu pada ibu primigravida yang mengalami ketakutan atau kecemasan dapat menyebabkan frekuensi His masih jarang dan tidak teratur atau Incoordinate uterine action. Hal ini sebagaimana dinyatakan Liu (2008) bahwa incoordinate uterine action merupakan salah satu kelainan his, disini sifat his berubah, tonus otot uterus terus meningkat diluar his, dan tidak ada sinkronisasi kontraksi bagian-bagiannya.

Tidak ada koordinasi antara kontraksi bagian atas, tengah dan bawah yang menyebabkan his tidak efisien dalam mengadakan pembukaan. Kondisi ini cenderung terjadi jika ibu ketakutan, distres atau cemas seperti pada persalinan pertama, terutama jika ibu berusia lebih dari 35 tahun.

Pernyataan di atas sejalan dengan pendapat Bobak (2005) bahwa breast massage adalah rangsangan melalui serabut syaraf yang memacu hipofise posterior untuk melepas hormon oksitosin dalam darah. Stimulasi ini juga akan merangsang hipotalamus untuk melepas oksitosin dari hipofisis posterior. Stimulasi Oksitosin membuat sel-sel mioepitel di sekitar alveoli didalam kelenjar mamae berkontraksi sehingga peningkatan kontraksi uterus mulai terbentuk.Selain itu oksitosin berperan juga memacu kontraksi otot rahim, sehingga mempercepat proses persalianan dan mengurangi perdarahan setelah persalinan. Pemijatan payudara dan stimulasi payudara tampaknya memfasilitasi pelepasan oksitosin dari kelenjar hipofisis posterior (Harnani 2010).

\section{KESIMPULAN}

Sebagian besar ibu bersalin dengan kala I lama sebelum diberikan breast massage mempunyai frekuensi His dalam kategori tidak ada kontraksi, yaitu sebanyak 21 orang $(52,5 \%)$. Sebagian besar ibu bersalin dengan kala I lama setelah diberikan breast massage mempunyai frekuensi His dalam kategori teratur, yaitu sebanyak 32 orang $(80,0 \%)$. Terdapat perbedaan kontraksi uterus sebelum dan setelah dilakukan Breast Massage terhadap peningkatan kontraksi uterus pada ibu bersalin kala I lama $(\mathrm{t}=8,862, \mathrm{p}$ value $=0,000)$.

\section{DAFTAR PUSTAKA}

Atun Raudotul Ma'rifah dan Surtiningsih. Efektifitas Tehnik Counter Pressure Dan Endorphin Massage Terhadap Nyeri 
Persalinan Kala 1 Pada

Ibu Bersalin Di Rsud

Ajibarang. Diakses

melalui:

http://download.portalgaru

da.org/article.php, tanggal

18 November 2015.

Anisa Magfuroh. 2012. FaktorFaktor Yang Berhubungan Dengan Nyeri Persalinan Kala I Fase Aktif Di Ruang Bersalin Rumah Sakit Umum Kabupaten Tangerang. Diakses melalui http://repository.uinjkt.ac.i d.pdf, tanggal 20 November 2015.

Azwar, Saifuddin. 2010. Metode Penelitian. Yogyakarta: Pustaka Pelajar.

Cunningham, Garyy F. 2006. Obstetri William Edisi 21. Jakarta: EGC.

Depkes 2008 Partograf.

Dhiantoro. 2012. Massage. Diakses melalui http://radewisekarmelati.blogspot. com/ p/masase.html, tanggal 4 Desember 2015

Eka Azrianti, dkk. Hamil: Mau Melahirkan Oksitosin Pelancar Kelahiran. Diakses melalui https://www.google.com/u $\mathrm{rl}$ ? $\mathrm{sa}=\mathrm{t} \& \mathrm{rct}=\mathrm{j} \& \mathrm{q}=\&$ esrc $=\mathrm{s}$
$\&$ source $=$ web\&cd $=1 \&$ cad $=$ rja\&uact $=8 \&$ ved $=0$ ahUK EwjN4dz_jLrJAhVFL6Y KHazFC24QFggcMAA\&u $\mathrm{rl}=\mathrm{https} \% 3 \mathrm{~A} \% 2 \mathrm{~F} \% 2 \mathrm{Ftrim}$ anjuniarso.files.wordpress. com $\% 2$ F $2008 \% 2 F 02 \% 2 F h$ amil.doc, tanggal 1 Desember 2015.

Emi Sutrisminah, dkk. Benefits Of Breast Massage On Postpartum Uterine Involution. Diakses melalui https://www.google.com/u $\mathrm{rl}$ ? $\mathrm{sa}=\mathrm{t} \& \mathrm{rct}=\mathrm{j} \& \mathrm{q}=\&$ esrc $=\mathrm{s}$ $\&$ source $=$ web $\&$ cd $=5 \& \mathrm{cad}$ $=$ rja\&uact $=8 \& v e d=0$ ahUK Ewip58vk_LnJAhWVB44 KHeaKDaAQFgg4MAQ\& url=http $\% 3 \mathrm{~A} \% 2 \mathrm{~F} \% 2 \mathrm{Fejou}$ rnal.stikesmukla.ac.id, tanggal 1 Desember 2015.

Evelyn, 2000. Anatomi Dan

Fisiologi Untuk

Paramedis. Jakarta :

Gramedia Pustaka Utama.

Hikayati, dkk. Komplementer Sebagai Upaya Untuk Mengatasi Dan Mencegah Komplikasi Pada Penderita Hipertensi Primer Di Kelurahan Indralaya Mulya Kabupaten Ogan Ilir. Diakses melalui https://www.google.com/u $\mathrm{rl}$ ? $\mathrm{sa}=\mathrm{t} \& \mathrm{rct}=\mathrm{j} \& \mathrm{q}=\& \operatorname{esrc}=\mathrm{s}$ 
$\&$ source $=$ web $\& c d=1 \& \mathrm{cad}$ $=$ rja\&uact $=8 \&$ ved $=0 \mathrm{ahUK}$ EwjecuIpb_JAhXII44KHTUQ CV0QFggcMAA\&url=htt p\%3A\%2F\%2Fejournal.un sri.ac.id $\% 2$ Findex.php $\% 2$

Fjpsriwijaya $\% 2$ Farticle $\% 2$
Fdownload\%2F1605\%2F6 31\&usg=AFQjCNGbPcL Udeo0wVSH8pLbFUPdO cy4xQ, tanggal 4 Desember 2015. 